\title{
Therapeutic Effect of Changing Working Environment on Musculoskeletal Disease
}

\author{
Hyunje Lee \\ Seoul International School, 15 Seongnam-daero, 1518 beon-gil, Sujeong-gu, Seongnam-si, Gyeonggi-do, 13113, South Korea; \\ 1101brian.lee@gmail.com
}

\begin{abstract}
Laborers required to do repetitive manual work are often diagnosed with musculoskeletal diseases and are advised by doctors to change their working environments. However, laborer patients tend to rely more heavily on medicines for immediate pain relief than changing their working environment due to job requirements, habits, short-term approach to alleviation, or lack of awareness. The therapeutic efficacy of changing working environments seems to be high, but to date, there has been no empirical or statistical study to support and prove this point. This paper seeks to quantify the pain relief and symptom alleviation achieved by the change in working environment of physical laborers, independent of medication. During the course of patients' treatments, the degree of change in working conditions and the degree of pain were recorded, and a correlation analysis was conducted to examine the relation between the two variables. Results show that improvements on patients' working conditions lead to a statistically significant degree of pain and symptom alleviation $\left(R^{\wedge} 2\right.$ value of 0.511 when $\left.p<0.01\right)$. This verifies empirically that the patients who changed their working conditions more actively had greater pain relief. Implications of the results and suggestions for further study are discussed.

KEYWORDS: Translational Medical Sciences; Disease Prevention; Musculoskeletal disease; Occupational medicine; Working environment.
\end{abstract}

\section{- Introduction}

The musculoskeletal diseases that laborers tend to have are studied in the field of occupational medicine. ${ }^{1}$ Occupational medicine aims to improve the health of people working in industrial fields and prevent diseases among them, ${ }^{2}$ whether that be occupational diseases or non-occupational diseases. As society became increasingly competitive after industrialization, there was a rapid spread of occupational diseases such as pneumoconiosis in coal mines, which became a big problem and instilled in people an awareness of occupational diseases. ${ }^{3}$

In the past, occupational diseases revolved around chemical addiction and cancer caused by carcinogenic environments. However, as the awareness of musculoskeletal diseases widened, people not only started to care about harmful environmental factors in workplaces, but also personal disposition and daily activity habits of workers that the workplace builds. ${ }^{4}$

Musculoskeletal disorders refer to physical disorders caused by factors such as repetitive movements, use of excessive force, mechanical stress, static or improper posture, local vibrations, and body contact with sharp surfaces. They usually occur in muscles and ligaments of the neck, shoulder, waist, and upper and lower limbs. The high-risk occupational groups include computer users, packaging workers, polishers and craftsmen, sheet metal workers, parts assemblers, auto mechanics, and manual workers. Patients who visit the hospital for musculoskeletal disorders are usually at a stage in which the pain recurs even after several days and weeks, and causes difficulty in performing their work. Common types of musculoskeletal disorders include lateral epicondylitis of elbow, chronic shoul- der and lumbar, cervical sprain, shoulder rotator cuff disease, myofascial pain syndrome, and chronic ankle sprain. ${ }^{5}$

Since the main cause of Work-related Musculoskeletal Diseases (WMSD) is the patients' working environment, patients are often prescribed actions to adjust their working environment as well as to take medication. However, the majority of patients are either unaware of the necessity of adjusting their working environment or unable to make those adjustments due to the nature of their occupation. ${ }^{6}$ Moreover, there are numerous patients who believe that taking medication would be better than making fundamental changes in their working environments to relieve their pain.

Previous studies and guidelines have issued multiple potential causative factors and preventive measures of WMSDs. This includes their relationship to adjusting working conditions; however, it is not easy to find studies that have reviewed the specific influence of change in working conditions in regard to the therapeutic effect in WMSDs. The aim of this study, therefore, was to empirically understand how improvement of the working environment affects pain relief in musculoskeletal disorders. This study is not an invasive experiment, but an observational study that analyzes the statistical correlation of pain relief and the degree of change in working environment during the treatment process of musculoskeletal disorders.

\section{- Literature Review}

Work-related Musculoskeletal diseases (WMSDs) are defined as an illness that results from physical risk factors such as repetitive action, biomechanical overload, and inappropriate working postures in the course of occupational activities. ${ }^{7}$ Their 
symptoms often comprise pain, stiffness, loss of strength, and neuromuscular control in body parts like neck, shoulder, spine, as well as upper and lower extremities. ${ }^{8}$

There are three main causative characteristics of WMSDs. The first causative characteristic is repetitiveness and use of excessive force. ${ }^{7,9}$ Strong muscle contraction and repetitive motion causes injuries in both muscular and tendinous tissues as well as inflammation. Examples of WMSDs associated with these characteristics include Carpal Tunnel Syndrome, Rotator Cuff Tendinitis, and Trigger Finger. Another characteristic is posture and physical stress. Inappropriate posture and physical stress during occupational activities cause the build-up of intramuscular pressure and ultimately trigger chronic pain in certain regions. ${ }^{7,9}$ Examples of WMSDs caused by this characteristic include Visual Display Terminals (VDT) syndrome and chronic neck sprain. The last causative characteristic is psychological stress, which plays a significant role in certain WMSDs in developing into chronic pain. ${ }^{10}$ The ultimate goal of the WMSD treatments is to relieve the associated symptoms and to enable the workers to return to work under good health conditions. Those treatments include symptom relief with the use of an anti-inflammatory medicine, resting, use of ice or heating pad, and continuous joint exercise. ${ }^{11}$ The prognosis of WMSDs is good in the initial stage with conservative treatment, but those symptoms are highly likely to develop into a chronic disease due to the difficulty in changing the working environments. Thus, consistent monitoring and care are necessary for the good prognosis of the patients. ${ }^{12}$

The Center for Disease Control and Prevention in the US has investigated the preventive measures for each cause ofWMSDs. In the case of having to complete a series of repetitive motions, patients should make use of mechanical assist devices, or find a less stressful position that requires an alternative form of motion. Secondly, in the case of performing strength-requiring work, patients should use mechanical devices that reduce the physical stress. ${ }^{13}$ For example, using a drilling machine instead of a punch grip device to complete work. Third, in the case of inappropriate working stature, patients should avoid extreme range of motion of certain body parts and adjust the working facilities to alleviate musculoskeletal stress. For example, a person who holds a job that demands precise use of fingers should provide support on his or her forearm to reduce stress that is applied on his or her arm and elbow muscles. ${ }^{14}$ For patients with lower back pain, lifting an object should be done by bending their knees instead of bending their spine.

Previous studies have addressed the multiple causative factors and preventive measures of WMSDs including their relationship to adjusting working conditions as described above. However, it is hard to find a study about how the change in working conditions is statistically connected with the pain relief of WMSD patients. If there is no statistically significant difference in pain relief between the group with an improved working environment and the group without a change in working environment, factors that have a greater impact on treatment than a changed working environment can be prioritized more in treatment. For example, it could be the case that the more important consideration is how early the medication is administered, or the strength of the medication. On the other hand, if there is a statistically more significant correlation between the degree of working condition change and pain scale, then the empirical data could be presented to patients who want to rely solely on medication to urge the willingness to improve their working environment.

\section{- Methods}

\section{Subject:}

Data collection for this study was conducted at Central Hospital located in Siheung, Gyeonggi province, South Korea, from December 2020 to April 2021, based on doctors' cooperation and patients' consent to participate in this research. The study population comprised patients who visited the Orthopedic Outpatient Department of the Central Hospital that had exhibited the following WMSDs; medial and lateral epicondylitis of the elbow (tennis elbow), shoulder joint rotator cuff tendinitis, Visual Display Terminals (VDT) syndrome, chronic wrist sprain, chronic back sprain (lumbar disc herniation), and Carpal tunnel syndrome (CTS). The WMSDs investigated in this study are:

- Medial/Lateral Epicondylitis of elbow: swelling of the tendons that bend your wrist backward away from your palm, commonly known as tennis elbow ${ }^{15}$

- Shoulder joint rotator cuff tendinitis: pain and swelling of the cuff tendons and the surrounding bursa caused by repetitive overload in the shoulder ${ }^{16}$

- Visual Display Terminals (VDT) syndrome or chronic neck sprain: pain in neck and shoulders associated with shoulder-arm-neck syndrome, fatigued eyes and foreign sensation, skin conditions and neuropsychiatric problems and other musculoskeletal symptoms ${ }^{17}$

- Chronic wrist sprain: repeated injury to the ligaments of the wrist commonly caused by repetitive overuse of the wrist $^{18}$

- Lumbar Disc Herniation: problem with one of the rubbery cushions (disks) that sit between the individual bones (vertebrae) that stack to form the spine ${ }^{19}$

- Carpal tunnel syndrome: pain in the wrist that occurs when the median nerve is compressed as it passes through the carpal tunnel ${ }^{20}$

\section{Procedure (Data Collection):}

All patients who visited the orthopedic outpatient department were educated on ways to adjust their occupational conditions and received medication treatment and physiotherapy as per usual. Analgesics were prescribed as medication to all patients, but they were guided to take it only when in severe pain and not regularly. Since analgesics are a temporary pain killer, they do not cure the root cause of the disease. The patients who agreed to participate in this study were followed up every week for the successive 6 weeks for data collection. Any patient who did not visit the hospital regularly was followed up by a phone call. All information was collected with the consent of each patient after IRB (Institutional Review Board) approval.

The data collected in this research included age, sex, occupation, contact, diseases, symptom, degree of pain which 
was measured in Numeric Pain Scale(NPS), and degree of working condition change in a scale of 1 3 in which " 1 " indicates barely changed and " 3 " indicates actively changed. The patient's pain scale was measured in a scale of 0 to 10 , in which 10 is the most painful and 0 is not painful at all, and the degree of pain was recorded starting from the first day of the visit. Every week afterward, the patients were asked about their pain scale in-person, through phone calls, or via text messages, and the degree of change in their pain was recorded for six weeks. Figure 1 is the Numeric Pain Scale used in this study, and Figure 2 is an example of a text message sent to patients in this study.

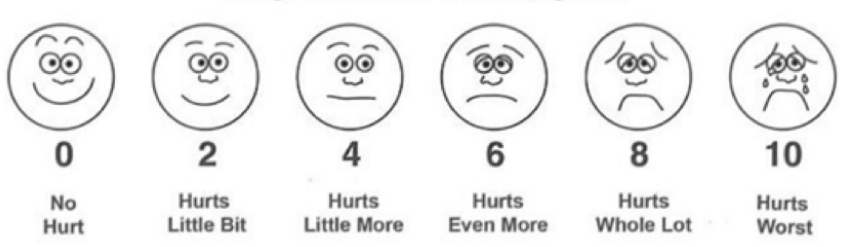

Figure 1: Numeric Pain Scale used in this study.

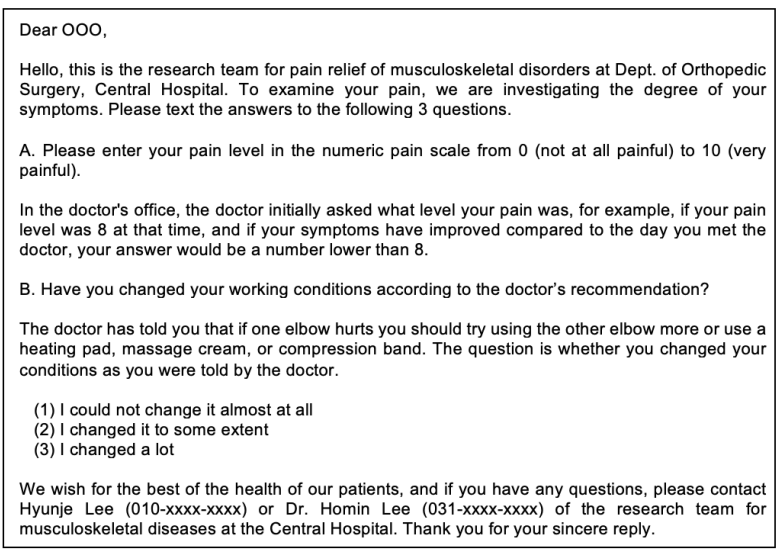

Figure 2: Text message to monitor patients' working condition change and NPS.

\section{Analysis Methodology:}

1. Main data collection was the NPS and the change in working conditions for each patient in the span of six weeks, in addition to their symptoms.

2. For the NPS, the difference between week one and week six was used for analysis as NPS indicates the degree of pain relief of a patient. The patient who had his or her pain relieved the most in the six weeks the study took place would have a relatively greater NPS than other patients.

3. The data for change in working condition, where the patients rated their own changes in working conditions from 1 (barely changed) to 3 (actively changed), was used in the analysis by calculating the average of the numerical data over the six weeks. The calculated average value indicates how active the patient was in changing their working conditions.

4. The correlation of NPS vs Average Working Condition Change was graphed as a scatterplot of 52 data points. The derived line of best fit of the scatterplot was used to calculate the $\mathrm{p}$-value to determine the statistical significance of the data.

5. Data were collected from December 2020 and took place for the following five months until six weeks' length of data for all of the participants was recorded.
- Results and Discussion

Data from a total of 62 patients including 46 males and 16 females were collected initially. During the six-weeks span, 10 patients whose follow-up data were not sufficiently collected were excluded from the study; hence 52 patients were subjects in the final study. Average age of the patients was 46 years old. Occupations of the patients were mainly laborers such as factory workers, cooks, and computer workers, who are required to complete repetitive manual work. Types of musculoskeletal disease included $50 \%$ of the patients with elbow lesion (lateral epicondylitis of elbow in 26 patients), $17 \%$ with shoulder lesion (rotator cuff disease in 3 patients, chronic shoulder sprain in 6 patients), $15 \%$ with foot and ankle lesion (plantar fasciitis in 3 patients, chronic ankle sprain in 5 patients), 10\% with wrist and hand lesion (chronic wrist sprain in 4 patients, trigger finger in 1 patient), $6 \%$ with lumbar lesion (Herniated intervertebral disc in 3 patients), and $4 \%$ with cervical lesion (Visual Display Terminal syndrome in 1 patient, chronic neck sprain 1 patient). Data collected from the 52 patients are shown in Table 1. Data include their sex, age, occupation, disease, as well as their Numeric Pain Scale, which is the pain difference between week one and week six, and the Average Working Condition Change ranging from 1(barely changed) to 3 (actively changed) (Table 1).

Table 1: Collected Data.

\begin{tabular}{|l|l|l|l|l|l|l|}
\hline No & Sex & Age & Occupation & Diesease & $\begin{array}{l}\text { Delta } \\
\text { NPS }\end{array}$ & AVG WC \\
\hline 1 & M & 35 & factory worker & $\begin{array}{l}\text { Lateral } \\
\text { epicondylitis }\end{array}$ & 2 & 2.17 \\
\hline 2 & M & 36 & factory worker & $\begin{array}{l}\text { Lateral } \\
\text { epicondylitis }\end{array}$ & 4 & 2.50 \\
\hline 3 & F & 37 & factory worker & $\begin{array}{l}\text { Lateral } \\
\text { epicondylitis }\end{array}$ & 3 & 2.17 \\
\hline 4 & M & 38 & welder & $\begin{array}{l}\text { Lateral } \\
\text { epicondylitis }\end{array}$ & 4 & 2.33 \\
\hline 5 & M & 42 & fisherman & $\begin{array}{l}\text { Lateral } \\
\text { epicondylitis }\end{array}$ & 5 & 2.50 \\
\hline 6 & F & 42 & factory worker & $\begin{array}{l}\text { Lateral } \\
\text { epicondylitis }\end{array}$ & 3 & 2.20 \\
\hline 7 & M & 50 & factory worker & $\begin{array}{l}\text { Lateral } \\
\text { epicondylitis }\end{array}$ & 4 & 2.33 \\
\hline 8 & M & 43 & chef & $\begin{array}{l}\text { Carpal tunnel } \\
\text { syndrome }\end{array}$ & 5 & 2.33 \\
\hline 9 & M & 40 & $\begin{array}{l}\text { Production } \\
\text { manager }\end{array}$ & $\begin{array}{l}\text { Lateral } \\
\text { epicondylitis }\end{array}$ & 4 & 2.50 \\
\hline 10 & F & 57 & factory worke & $\begin{array}{l}\text { Lateral } \\
\text { epicondylitis }\end{array}$ & 5 & 2.67 \\
\hline 11 & M & 42 & factory worker & $\begin{array}{l}\text { Lumbar } \\
\text { HIVD }\end{array}$ & 5 & 2.50 \\
\hline 12 & F & 60 & housewife & $\begin{array}{l}\text { Lateral } \\
\text { epicondylitis }\end{array}$ & 4 & 2.50 \\
\hline 14 & M & 26 & $\begin{array}{l}\text { machine } \\
\text { transporter }\end{array}$ & $\begin{array}{l}\text { Chronic } \\
\text { shoulder sprain }\end{array}$ & 3 & 2.33 \\
epicondylitis & 4 & 2.33 \\
\hline
\end{tabular}




\begin{tabular}{|c|c|c|c|c|c|c|}
\hline 15 & M & 44 & factory worker & $\begin{array}{l}\text { Lateral } \\
\text { epicondylitis }\end{array}$ & 4 & 2.67 \\
\hline 16 & M & 42 & factory worker & $\begin{array}{l}\text { Lateral } \\
\text { epicondylitis }\end{array}$ & 5 & 2.17 \\
\hline 17 & M & 58 & cycling & $\begin{array}{l}\text { Rotator cuff } \\
\text { disease }\end{array}$ & 3 & 2.25 \\
\hline 18 & M & 55 & factory worker & $\begin{array}{l}\text { Chronic wrist } \\
\text { sprain }\end{array}$ & 3 & 2.50 \\
\hline 19 & M & 47 & gas station & $\begin{array}{l}\text { Lateral } \\
\text { epicondylitis }\end{array}$ & 0 & 1.17 \\
\hline 20 & M & 46 & factory worker & $\begin{array}{l}\text { Lateral } \\
\text { epicondylitis }\end{array}$ & 2 & 2.50 \\
\hline 21 & M & 54 & factory worker & $\begin{array}{l}\text { Lateral } \\
\text { epicondylitis }\end{array}$ & 1 & 1.50 \\
\hline 22 & M & 26 & carpenter & $\begin{array}{l}\text { Chronic } \\
\text { shoulder sprain }\end{array}$ & 3 & 2.00 \\
\hline 23 & $\mathrm{~F}$ & 49 & $\begin{array}{l}\text { computer } \\
\text { worker }\end{array}$ & $\begin{array}{l}\text { Chronic } \\
\text { shoulder sprain }\end{array}$ & 1 & 1.75 \\
\hline 24 & $\mathrm{~F}$ & 48 & $\begin{array}{l}\text { computer } \\
\text { worker }\end{array}$ & $\begin{array}{l}\text { Chronic neck } \\
\text { sprain }\end{array}$ & 2 & 1.50 \\
\hline 25 & $\mathrm{~F}$ & 46 & $\begin{array}{l}\text { computer } \\
\text { worker }\end{array}$ & $\begin{array}{l}\text { Chronic back } \\
\text { sprain }\end{array}$ & 5 & 2.17 \\
\hline 26 & M & 49 & factory worker & $\begin{array}{l}\text { Chronic ankle } \\
\text { sprain }\end{array}$ & 5 & 2.17 \\
\hline 27 & $\mathrm{~F}$ & 42 & factory worker & $\begin{array}{l}\text { Rotator cuff } \\
\text { disease }\end{array}$ & 1 & 1.67 \\
\hline 28 & $\mathrm{~F}$ & 53 & factory worker & $\begin{array}{l}\text { Rotator cuff } \\
\text { disease }\end{array}$ & 2 & 2.00 \\
\hline 29 & M & 23 & engineer & Ankle sprain & 5 & 2.33 \\
\hline 30 & M & 58 & factory worker & Plantar fasciitis & 3 & 2.33 \\
\hline 31 & M & 41 & delivery service & $\begin{array}{l}\text { Chronic } \\
\text { shoulder sprain }\end{array}$ & 2 & 2.00 \\
\hline 32 & $\mathrm{~F}$ & 53 & athlete & $\begin{array}{l}\text { Chronic } \\
\text { shoulder sprain }\end{array}$ & 6 & 2.00 \\
\hline 33 & M & 26 & $\begin{array}{l}\text { computer } \\
\text { worker }\end{array}$ & $\begin{array}{l}\text { Chronic knee } \\
\text { sprain }\end{array}$ & 3 & 2.00 \\
\hline 34 & $\mathrm{M}$ & 52 & factory worker & $\begin{array}{l}\text { Chronic wrist } \\
\text { sprain }\end{array}$ & 2 & 2.00 \\
\hline 35 & M & 38 & factory worker & $\begin{array}{l}\text { Chronic wrist } \\
\text { sprain }\end{array}$ & 1 & 2.00 \\
\hline 36 & M & 58 & factory worker & $\begin{array}{l}\text { Lateral } \\
\text { epicondylitis }\end{array}$ & 4 & 1.33 \\
\hline 37 & $\mathrm{M}$ & 26 & factory worker & $\begin{array}{l}\text { Chronic } \\
\text { shoulder sprain }\end{array}$ & 5 & 2.50 \\
\hline 38 & $\mathrm{M}$ & 57 & factory worker & $\begin{array}{l}\text { VDT, } \\
\text { Cervical- } \\
\text { HIVD }\end{array}$ & 4 & 2.50 \\
\hline 39 & M & 50 & factory worker & Plantar fasciitis & 4 & 2.50 \\
\hline 40 & $\mathrm{M}$ & 64 & factory worker & $\begin{array}{l}\text { Lateral } \\
\text { epicondylitis }\end{array}$ & 3 & 1.83 \\
\hline 41 & M & 37 & factory worker & $\begin{array}{l}\text { Lateral } \\
\text { epicondylitis }\end{array}$ & 3 & 2.00 \\
\hline
\end{tabular}

\begin{tabular}{|l|l|l|l|l|l|l|}
\hline 42 & F & 41 & factory worker & Plantar fasciitis & 5 & 2.25 \\
\hline 43 & M & 57 & $\begin{array}{l}\text { computer } \\
\text { worker }\end{array}$ & $\begin{array}{l}\text { Lateral } \\
\text { epicondylitis }\end{array}$ & 1 & 1.75 \\
\hline 44 & F & 58 & driver & $\begin{array}{l}\text { Lumbar } \\
\text { HIVD }\end{array}$ & 3 & 2.25 \\
\hline 45 & M & 36 & $\begin{array}{l}\text { fcomputer } \\
\text { worker }\end{array}$ & $\begin{array}{l}\text { Lumbar } \\
\text { HIVD }\end{array}$ & 2 & 1.67 \\
\hline 46 & M & 50 & factory worker & Trigger finger & 1 & 1.75 \\
\hline 47 & M & 61 & animal breeding & $\begin{array}{l}\text { Lateral } \\
\text { epicondylitis }\end{array}$ & 3 & 2.3 \\
\hline 48 & M & 52 & factory worker & $\begin{array}{l}\text { Lateral } \\
\text { epicondylitis }\end{array}$ & 0 & 1.25 \\
\hline 49 & M & 60 & factory worker & $\begin{array}{l}\text { Lateral } \\
\text { epicondylitis }\end{array}$ & 1 & 1.25 \\
\hline 50 & M & 41 & factory worker & $\begin{array}{l}\text { Lateral } \\
\text { epicondylitis }\end{array}$ & 0 & 1.00 \\
\hline 51 & M & 26 & factory worker & $\begin{array}{l}\text { Lateral } \\
\text { epicondylitis }\end{array}$ & 4 & 2.33 \\
\hline 52 & F & 47 & teacherr & $\begin{array}{l}\text { Lateral } \\
\text { epicondylitis }\end{array}$ & 3 & 2.50 \\
\hline
\end{tabular}

*NPS: Numeric Pain Scale Difference between week one and week six given that 10 is the most painful and 0 is not painful at all

** AVG WC: Average change made in working conditions given that ' 1 ' is the least change and ' 3 ' is an active change.

After having followed the data collection and analysis steps stated in the methodology, the result showed that this data set has a $R 2$ value of 0.511 when the $\mathrm{p}$-value is $<0.01$, making the correlation of the dataset statistically significant. Figure 3 shows the scatterplot between the change in NPS and average working conditions. It shows that the patients who changed their working conditions more actively had greater pain relief. Delta NPS vs. AVG WC

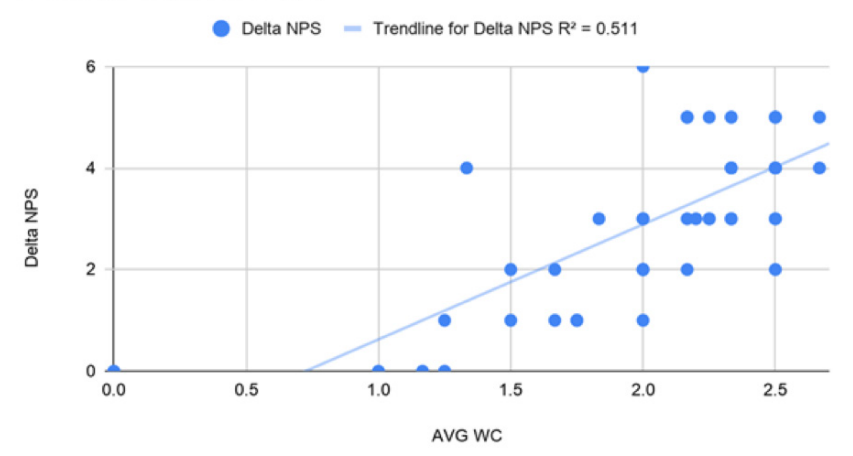

Figure 3: Scatterplot between Delta Numeric Pain Scale(NPS Difference between week one and week six given that 10 is the most painful and 0 is not painful at all) and Average working condition change. (Average change made in working conditions given that ' 1 ' is the least change and ' 3 ' is an active change.)

\section{Conclusion}

The study aimed to analyze how improved working conditions affect pain relief in people with musculoskeletal disorders caused by repetitive labor, biomechanical overload, and inappropriate working postures. Studies have shown that working condition change is significantly correlated with the 
pain relief in musculoskeletal diseases, implying that the better the working environment, the more pronounced the pain relief, independent of medication intake. This study was significant in that it helped convince patients of the need to improve their working environment by providing clear empirical data to patients who tend to rely more on painkillers than improving their working environment.

In addition, it has been reconfirmed that the cause of pain in musculoskeletal diseases is a repetitive working environment, so it indicates a need for flexible working environment policies for workers. Even when the patients try to take the advice of improving their working environment, it is often difficult to do by themselves because the working environment is institutionally inflexible, or because of the patients' habits or lack of awareness. In order to reduce the incidence of musculoskeletal diseases among workers in industrial or working sites, the mechanical environment and the physical space for an individual worker needs to allow for different postures and patterns. This would ensure that working posture could be changed from time to time rather than continuously repeating a fixed motion. Decreasing repetition will eventually increase the working productivity, benefiting the employers as well as the workers. Hence, it is necessary to develop public health and labor policies in consideration of such universal benefits. Also, patients may be provided with a campaign or brochure-like announcements to individually learn about certain requirements of working environments for their health.

There are a few limitations to this study. First of all, the NPS and the 1,2, 3 scale in which the patients rated the extent of change in working condition do not have a standardized or scientific method to distinguish the meticulous difference between "1" and "2". The numeric scales were employed to derive the extent of patients' perception into quantitative indicators. People who are sensitive to pain might rate a higher score in the NPS than those who are less sensitive.

The second limiting factor is that there could be a notable difference in the data between patients who physically visited the hospital more often and the patients who participated in the data collection mostly through mobile phone communication after their first visit to the hospital. The patients who physically visited the hospital more often may generally have had greater decrease in the NPS as time passed, perhaps because they would have been more proactive in curing the disease.

Another limitation is that there were multiple patients during the study who failed to consistently follow up with the data collection due to their personal schedule, government safety protocols due to the pandemic, and financial difficulties caused by COVID-19. These data were excluded from the analysis, reducing the number of subjects in the study.

Lastly, in this study, painkillers were prescribed in addition to changing working conditions, to allow patients to take them intermittently if not regularly. Painkillers may have contributed to the natural healing of the disease over time by temporary pain relief, even without fundamental treatment or a change in working condition.

More sophisticated and concrete analysis by supplementing these limitations could be suggested for further studies. In the future, it would be interesting to study various reasons why patients cannot change their working conditions easily. If the pain decrease mechanism in each reason is investigated, more personalized treatment and consulting would be possible. In additon, it would be meaningful if the dose of medication was analyzed as a variable to measure the impact on pain decrease. Analysis between groups that only change their working environment without medication treatment and groups that take painkillers intermittently, or comparing patients' pain relief with working condition changes only among a group with the same number of visits to the hospital, would garner more insight into the degree of impact of changing working environment and provide more specific implications in further treating musculoskeletal disorder.

\section{- Acknowledgements}

I would like to express my gratitude to my AP Chemistry teacher Dr. Rose Tyvand from Seoul International School and Dr. Homin Lee from Siheung Central Hospital for advising and supporting me with data collection and analysis in the study.

\section{References}

1. Magnavita, N.; Elovainio, M.; De Nardis, I.; Heponiemi, T.; Bergamaschi,A.EnvironmentalDiscomfort and Musculoskeletal Disorders. Occup. Med. (Lond.) 2011, 61 (3), 196-201.

2. Zenz, C. Occupational Medicine: Principles and Practical Applications. Year Book Medical Publishers 1989, 17 (1), 1273. https://doi.org/10.1177/140349488901700119.

3. Laney, A. S.; Weissman, D. N. Respiratory Diseases Caused by Coal Mine Dust. J. Occup. Environ. Med. 2014, 56 (Supplement 10), S18-S22.

4. Rom, W. N., \& Markowitz, S. B. Environmental and Occupational Medicine; Lippincott Williams and Wilkins: Philadelphia, PA, 2007.

5. Hong, J. Y., \& Koo, J. W. Medical Approach of Work-Related Musculoskeletal Diseases. Journal of the Ergonomics Society of Korea 2010, 29 (4), 473-478. https://doi.org/10.5143/ JESK.2010.29.4.473.

6. Sell, L., Lund, H. L., Holtermann, A., \& Søgaard, K. The Interactions between Pain, Pain-Related Fear of Movement and Productivity. Occupational Medicine 2014, 64 (5), 376-381. https://doi.org/10.1093/occmed/kqu056.

7. Punnett, L. \& Wegman, D. Work-Related Musculoskeletal Disorders: The Epidemiologic Evidence and the Debate. Journal of Electromyography and Kinesiology 2003, 14, 13-23. https://doi. org/10.1016/j.jelekin.2003.09.015.

8. Visser, B.; van Dieën, J. H. Pathophysiology of Upper Extremity Muscle Disorders. J. Electromyogr. Kinesiol. 2006, 16 (1), 1-16.

9. McCauley-Bush, P. Ergonomics: Foundational Principles, Applications, and Technologies; CRC Press: London, England, 2011.

10.Hagberg M., Silverstein B., Wells R., Smith M., Hendrick H., Carayon, P., \& Perusse, M. Work Related Musculoskeletal Disorders (WMSDs): A Reference Book for Prevention; Taylor \& Francis: London, England, 1995.

11.Lavdaniti, M., Tsiligiri, M., Sarpetsa, S., Tousidou, E., \& Chatzi, M. The Concept of "Care" as Perceived by Greek Nursing Students: A Focus Group Approach. International Journal of Caring Sciences 2013, 6 (3), 392-401.

12.Descatha, A., Roquelaure, Y., Chastang, J. F., Evanoff, B., Cyr, D., \& Leclerc, A. Work, Prognosis Factor for Upper Extremity Musculoskeletal Disorders? British Medical Journal 2009, 66 (5), 
351-352. https://doi.org/10.1136/oem.2008.042630.

13.Silvia, C. E., Bloswick, D. S., Lillquist, D., Wallace, D., \& Perkins, M. S. An Ergonomic Comparison between Mechanical and Manual Patient Transfer Techniques. Work 2002, 19 (1), 19-34.

14.Dennerlein, J. T., \& Johnson, P. W. Different Computer Tasks Affect the Exposure of the Upper Extremity to Biomechanical Risk Factors. Ergonomics 2006, 49 (1), 45-61. https://doi. org/10.1080/00140130500321845

15.Vaquero-Picado, A.; Barco, R.; Antuña, S. A. Lateral Epicondylitis of the Elbow. EFORT Open Rev. 2016, 1 (11), 391-397.

16.Factor, D.; Dale, B. Current Concepts of Rotator Cuff

Tendinopathy. Int. J. Sports Phys. Ther. 2014, 9 (2), 274-288.

17.Parihar, J. K. S.; Jain, V. K.; Chaturvedi, P.; Kaushik, J.; Jain, G.;

Parihar, A. K. S. Computer and Visual Display Terminals (VDT)

Vision Syndrome (CVDTS). Med J. Armed Forces India 2016, 72 (3), 270-276.

18.van Vugt, R. M.; Bijlsma, J. W.; van Vugt, A. C. Chronic Wrist

Pain: Diagnosis and Management. Development and Use of a New Algorithm. Ann. Rheum. Dis. 1999, 58 (11), 665-674.

19.Amin, R. M.; Andrade, N. S.; Neuman, B. J. Lumbar Disc

Herniation. Curr. Rev. Musculoskelet. Med. 2017, 10 (4), 507-516.

20.Genova, A.; Dix, O.; Saefan, A.; Thakur, M.; Hassan, A. Carpal

Tunnel Syndrome: A Review of Literature. Cureus 2020, 12 (3), e7333

\section{Author}

Hyunje Lee is a senior at Seoul International School in Korea. His experience of volunteering at a public clinic for underinsured immigrant workers in Korea for 5 years led to his passion for understanding the intricacies of Public and Global Health, the field in which he intends to study in the future. 